\title{
THE ELIMINATION OF THE SEX CHROMOSOMES FROM THE MALE-PRODUCING EGGS OF PHYLLOXERANS
}

\author{
T. H. MORGAN
}

From the Zoological Laboratory, Columbia University

TWENTY-NINE FIGURES

My studies of the life cycle of the phylloxerans of the hickories have shown first ('08) why the fertilized eggs produce only females, ${ }^{1}$ and second ('09) that the production of the males is caused by the elimination of a chromosome from the male-producing egg. ${ }^{2}$ One essential point in the life cycle still remained unexplained; namely, the cause of the production of small maleand large female-producing eggs. The differentiation of these two kinds of eggs precedes, in the life cycle, the formation of the true males and sexual females. It may appear therefore that the question of the sex determination antedates those changes that lead to the elimination of a chromosome from the male-producing egg, and, if so, the real question of sex determination might seem to lie deeper than the manouvres of the sex chromosomes. Until this point is cleared up the value of the chromosome hypothesis in sex determination may seem to hang in the balance.

I am now able to bring forward certain evidence which I believe throws light on this important topic and I am prepared to offer an hypothesis based on the new evidence, which, if true, substantiates the view that one of the essential changes in the formation of the large and the small eggs is connected with changes in the sex chromosomes.

${ }^{1}$ Proc. Soc. Exp. Biology and Medicine, vol. 5, 1908, and Science, vol. 29, 1909.

${ }^{2}$ Proc. Soc. Exp. Biology and Medicine, vol. 7, 1910. 
The main points that were described in my previous papers may be summarized as follows:

1. Two classes of sperm are produced in the male differing in the presence and absence of a pair of chromosomes. One class of sperm degenerates. It corresponds to the male-producing class of otherinsects. The other class produces functional spermatoza which entering the egg give rise to females only. These sperm correspond to the female-producing class of other insects.

2. The male-producing egg contains one less chromosome after the extrusion of its single polar body than it contained before this event. In a preliminary note ('10) I have stated how this elimination takes place and in the present paper I bring forward the evidence on which this statement was based.

3. The difference in size between the male-producing and the female-producing egg, before the former has extruded its polar body, proves that the predetermination of the males antedates the extrusion of the chromosome in the polar body of the (smaller) male-producing egg.

4. More male-producing individuals are the descendants of each stem-mother than female-producing individuals. The stemmother must give rise to two kinds of eggs, i. e., they must be different either before or after the polar body is extruded. The factor that differentiates these two kinds of eggs, was not discovered. It is this point that the evidence now brought forward may I hope help to elucidate.

THE DIFFERENCES IN THE CHROMOSOME GROUPS IN THE POLAR SPINDLES OF THE STEM-MOTHER'S EGG AND OF THE MALE AND FEMALE-PRODUCING EGGS

In my former paper ('09) I have figured ten equatorial plates of polar spindles of the eggs produced by the stem-mother. In all of these the sex chromosomes are of nearly the same size. In two other plates one chromosome is much smaller than the others, which is probably due to this chromosome having been cut by the knife. Failure to find the missing piece in the next section would not be significant, since it might be very difficult to find such a piece in the egg filled with yolk granules of about the same 
size as the chromosomes. Side views of the polar spindle, of which four are given, each with three chromosomes, show these to be of equal size. One of two cases of an egg nucleus (just prior to the formation of the spindle) also shows six equal chromosomes; the other case shows four equal chromosomes and one of double size that no doubt represents two chromosomes overlapping or else stuck together.

When these chromosome plates are compared with those of the female-producing egg shown in fig. LX, page 255 of my paper ('09), the size relations seem to be about the same. Only four plates of these eggs were found. I suspect that one of the equatorial plates that is assigned to a male-producing egg, namely, fig. $\mathrm{LX} ; K$, really belongs to a female-producing egg. Occasionally it is difficult, owing to the obliqueness of the sections, to make sure that a particular egg is a large or a small one. If this egg is excluded, or referred to the female-producing series, there remain fourteen equatorial plates of male-producing eggs. In all of them one chromosome is noticeably smaller than the rest. I can now add four more chromosome groups of male-producing eggs to this list, figs. 1, 2,3,4. Three of these are equatorial plates or just prior to that phase, and the fourth shows the chromosomes in the nucleus just prior to the spindle stage. They all contain five larger chromosomes, and one much smaller than the other five.

It is true that there is some variation in the relative size of the chromosomes in all of these figures, which makes it difficult to express exactly the relative sizes of the different chromosomes, and therefore I am aware of the danger of attempting to distinguish between the plates of the male- and female-producing eggs; yet the presence of the very small chromosome is so distinctive of the smaller eggs that I believe no error is committed in attributing to this difference at least a real significance.

If the two kinds of chromosomal groups just specified are significant one should expect to find a similar difference in the somatic cells of the individuals that give rise to these eggs, for since each of these individuals produces only one kind of egg (all the eggs found in one individual are male-producing or female- 
producing) this difference should be apparent on inspection of the somatic cells of these individuals. In my paper I have, in fact, given nine plates taken from young stages of the development of the embryo. Some of these figures, notably fig. VLII $C, E, I$, show six nearly equal chromosomes, while five of them, notably fig. VIII $A, B, D, F, G$ show five larger and one smaller chromosomes. When these drawings were made the importance
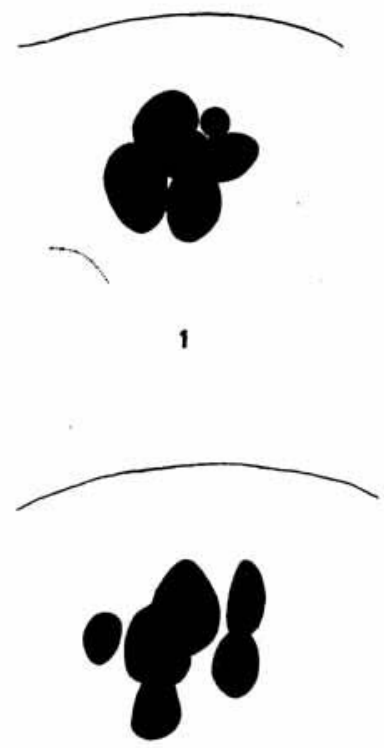

3

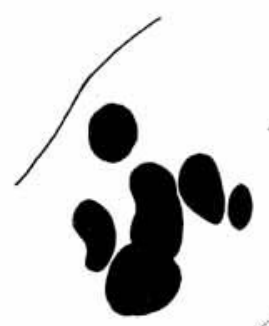

2

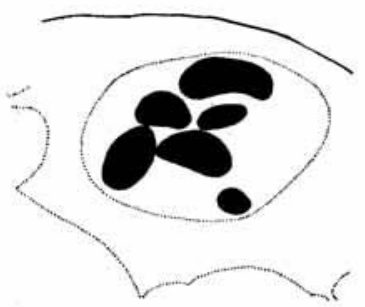

4

of the size relations was not appreciated, and the number of cases is too smail to be of great value, but it is significant, I think, that the two kinds of chromosome groups required by the hypothesis are actually represented in these figures.

It appears, then, probable that after the extrusion of the polar body of the egg of the stem-mother a change has taken place in those individuals that become the male-egg-producers. One chromosome has become smaller. 
THE DIVISION OF THE POLAR SPINDLE IN THE MALE- AND IN THE FEMALE-PRODUCING EGGS

A brief abstract of the results given in this section was published in the Proceedings of the Society of Experimental Biology and Medicine ${ }^{3}$ for May, 1910. In order to study the division of the polar spindle a large amount of new material was collected in the summer of 1909 which was cut and studied during the following winter. It has been most laborious to find eggs in which the polar spindle was in the process of division, and I wish to express my obligations to my assistant, Miss E. M. Wallace, who has found most of the new cases here figured.

In my former paper ('09) I described the anaphase of two eggs that seemed to be female eggs (see below), but none of the male eggs; and it is the latter that would be expected to give the critical evidence. This evidence was briefly stated in my preliminary note in 1910. I shall now give drawings of several anaphases of måle eggs that show beyond doubt that a lagging chromosome is present; that it passes to the outer pole, and forms a separate vesicle in the polar body.

The first case is shown in fig. 5 representing an anaphase of the polar spindle. Five chromosomes lie at the outer pole and five at the inner pole. In the middle of the spindle lies a double chromosome. It is relatively large and its two halves appear somewhat unequal. For reasons that appear later I shall speak of this as a single chromosome that has already divided into halves.

The second case is shown in fig. 6. Here also five chromosomes, somewhat elongated, lie at the outer pole and five at the inner pole of the spindle. In the middle of the spindle there is a double chromosome, its halves equal as far as can be determined.

The third case is shown in fig. 7. It represents a later stage; the polar body being in process of constricting from the egg. The group of chromosomes at the outer pole is now in process of division. Five chromosomes can be recognized, two dividing, and three having completed their division. At the inner pole

${ }^{3}$ Proc. Soc. Exp. Biology and Medicine, vol. 7, 1910. 

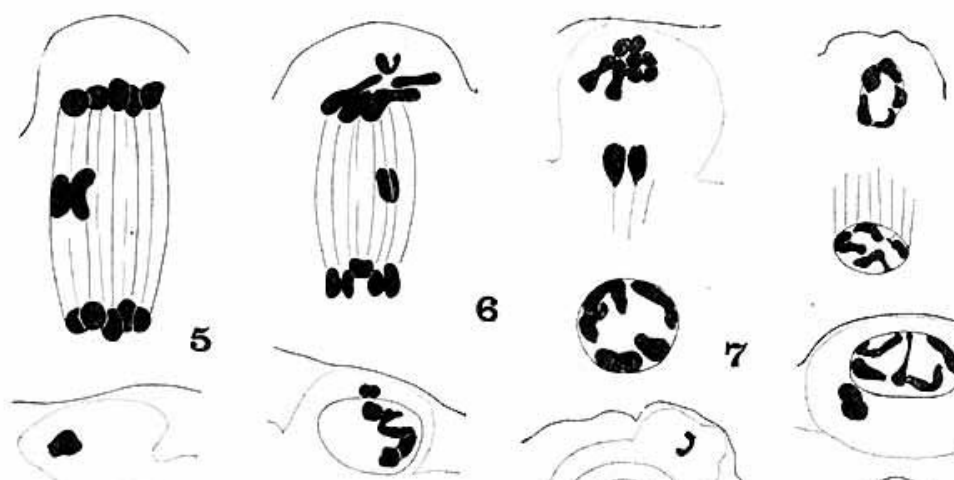

62

(3)

8

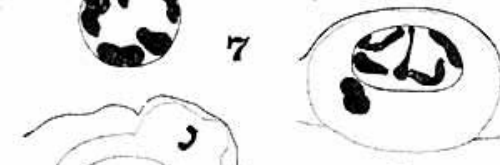

(ii)
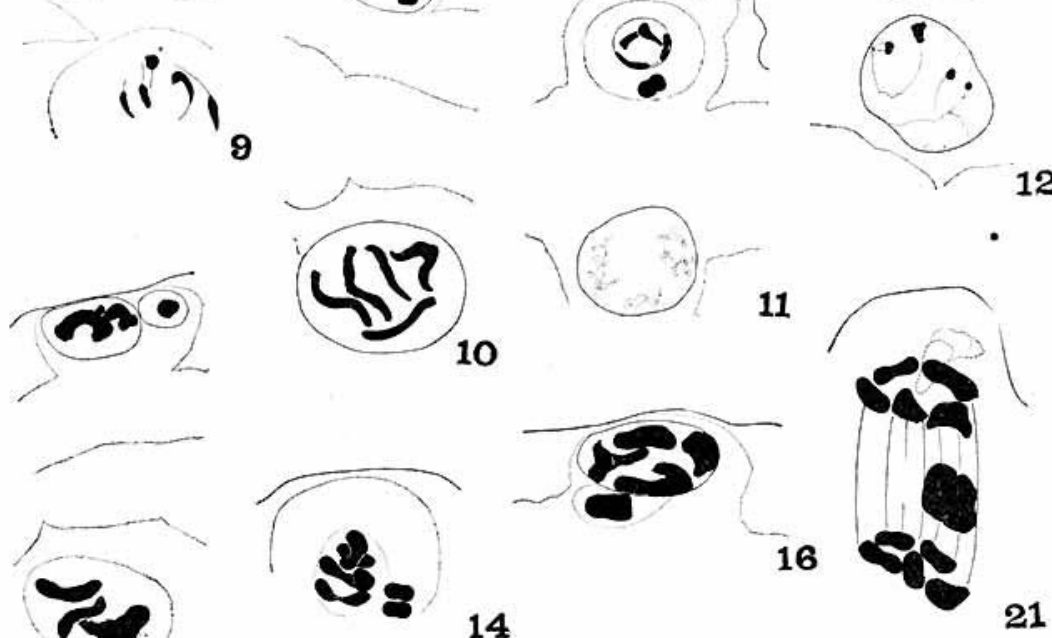

13
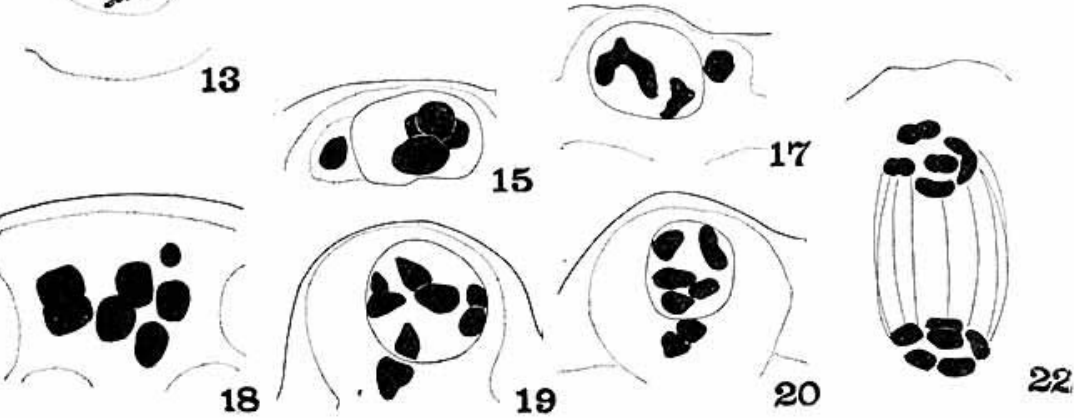
the nucleus has begun to form. It contains five distinct chromosomes. Midway between the poles is the lagging chromosome completely divided into equal or nearly equal parts. A few traces of the spindle fibers are discernible. This is the clearest case that I have found and shows very distinctly the conditions at this stage.

The next case, fig. 8 , is not so instructive, since the chromosomes in the inner nucleus have in one place seemingly stuck together so that only four bodies are seen. The lagging chromosome could not be found but the five outer chromosomes are distinct.

Fig. 9 shows the polar body nearly constricted off. The five inner chromosomes are clearly seen. The lagging chromosomes were not found and may have been fused with the lump of chromatin in the polar body that represents the massed chromosomes.

In fig. 10 (and in figs. 9, 11, 12 and 13) the egg nucleus is represented nearer the surface than in the actual section. The nucleus of the polar body contains a fused mass of chromatin. What appears to be the lagging chromosome lies on its outer wall, and is partially constricted into halves. The inner nucleus shows five equal or nearly equal chromosomes. As this is the only case observed where the lagging chromosome lies on the outer wall of the nucleus of the polar body, and as it is difficult to see how the chromosome could have reached this position; and moreover since the double body is smaller than the lagging chromosome in the other cases; it may be that this deeply staining body is not the lagging chromosome at all but a pair of displaced yolk granules. This interpretation is supported by the next case.

In this instance fig. 11 the inner nucleus is well formed and its chromosomes diffused or at least not stained. In the polar body there is a nucleus in which four chromosomes can be made out with the double lagging chromosome lying on the inner side of the nucleus. A yolk granule lies on the outer wall of the nucleus.

A similar stage is shown in the next figure, fig. 12. The inner or egg nucleus shows its contained chromosomes in process of 
becoming diffuse. The polar body is cut off from the egg; its nucleus contains five chromosomes, and lying near the nucleus is the large lagging chromosome divided into two parts.

In the next figure, fig. 13, the chromosomes, both in the polar body and in the egg nucleus, have fused. The preservation may have been poor. The lagging chromosome lies in a vesicle of its own to one side of the polar body nucleus.

The polar body of another egg, fig. 14, shows five chromosomes in its nucleus, three of which at least are elongated as though dividing. The lagging chromosome lies outside. Its two halves are separated and each half is slightly dumb-bell shaped.

Three other polar bodies are shown in figs. 15, 16, and 17 . Each shows the lagging chromosome outside of the nucleus; and in two cases surrounded by a partial vacuole of its own.

In addition to these new cases I have studied and redrawn some of the figures given in my formerpaper, restaining when necessary to better bring out the chromosomes. One of these, fig. 18, shows the equatorial plate of a male egg with one large chromosome (partly constricted), four intermediate, and one small chromosome. Two cases, figs. 19, 20, show polar bodies and their contained nucleus and the lagging chromosome outside. The third figure, fig. 21, shows the anaphase of an egg that I now interpret as a male egg. The interpretation of this anaphase figure is difficult because of the presence of a stained body near the center of the spindle. After staining and restaining several times it seems to me probable that this body is in reality a chromosome and not a yolk sphere as I formerly thought probable. Another sphere lies beyond the outer chromosome group and near it another body (in outline in the figure). Both of these seem to be in yolk spheres. At the inner pole five distinct chromosomes are present. If the stained body in the center of the spindle be interpreted as a chromosome the spindle bears a close resemblance to the spindle of the male-producing egg, but the egg is large, and mainly for this reason I was formerly inclined to think it a female egg. The case is doubtful and can not be interpreted with certainty. 
I have tried to find again all the polar body stages figured in my former paper in order to reëxamine them, but it has not been possible to discover several of them owing to the fading of the stain. I wished especially to reëxamine figs. $X ; N, P, Q$, which show the lagging chromosomes passing into the polar bodies, but have not succeeded in finding them again. All three represent the same spindle under different conditions. While these figures were drawn with as much care as possible I now realize that some of them might receive a clearer interpretation in the light of the information that I have gained from a new study of the polar spindle. One point is especially clear that in most cases the circle enclosing the chromosomes of the polar bodies of the male-producing egg was drawn so as to include the lagging chromosome, while in reality the ordinary chromosomes lie in one vesicle and the accessory in another clear area at the side of the latter. Thus in figs. $X ; C, G, I, L, M, R, S, T, U$, the sixth chromosome generally shown as bifid represents the lagging chromosome.

In the new preparations I have found only one anaphase of a female-producing egg, fig. 22. Fortunately this is a very clear case. Six chromosomes lie at each pole, and there is no lagging chromosome present. Three of the outer chromosomes are dumb-bell shaped. The only other cases of this kind of egg are the doubtful case, here refigured, fig. 21 , and the outer pole shown in my former paper in fig. $X ; K$.

\section{Summary}

The evidence shows that four of the five chromosomes of the male-producing egg divide equally when the polar body is formed. One chromosome lies in the middle of the spindle and becomes divided into equal parts. It finally passes out into the polar body, just before the latter cuts off, and fails in consequence to become incorporated in the nucleus of the polar body. In all these respects its behavior is closely similar to that of the lagging chromosome described by McClung for this chromosome in the spermatocytes of orthoptera. 
The six chromosomes of the female-producing egg appear to divide equally, so that the outer and the inner pole of the spindle get six chromosomes each.

One point of especial importance I have not been able to settle satisfactorily, namely, the fate of the smallest chromosome. Theoretically I should expect it to be the lagging chromosome. But the figures show the lagging as large as the rest. On the other hand it is equally clear that none of the others can be identified as the smallest - they appear to be of equal size. The evidence is therefore inconclusive either way. If the smallest is the lagging it must increase in size before it divides so that its size relations are changed.

\section{THE POLAR SPINDLES IN THE SEXUAL EGG}

Two questions of theoretical interest are involved in the anticipated reduction in the number of chromosomes in the sexual egg of the phylloxerans, namely, the number of the reduced chromosomes and their size relations. Whether the reduced number would be four or three could not be prophesied from the behavior of the chromosomes in the parthenogenetic series, for if, as I think, there are two small $x$-chromosomes attached to the two large $X$ 's, the former might separate at the 'reduction period' to form a smaller pair, giving four chromosomes or else remaining attached to the larger $X$ there would appear only three chromosomes. Six cases have been found showing clearly that the number of chromosomes in the sexual egg is three. I have found two eggs that show equatorial plates, figs. 23, 26; two eggs that show the chromosomes in the nucleus just before its resolution, figs. 27, 28; and two eggs that show side views figs. 24,25 . There can be no question that the reduced number is three. The size relations are more difficult to determine. In general it may be said that they are all of nearly the same size, although one of them generally appears larger than the other two. There is no such disparity in size between the largest and the smallest as that observed in the male-producing egg, which is a strong argument against my earlier suggestion that the smallest chromosome in the equatorial plate of the male- 
producing egg is formed by the union of the two small $x$ 's that leave their larger partners at this time and fuse in order that 'reduction' may occur. For, should this happen in the maleproducing egg in order to insure the separation of the two small

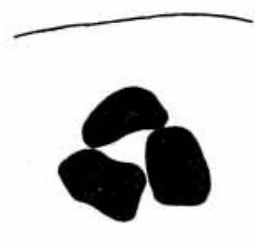

23

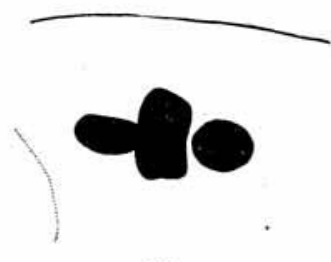

24

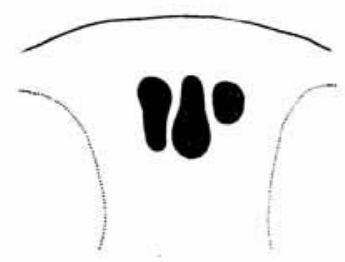

25
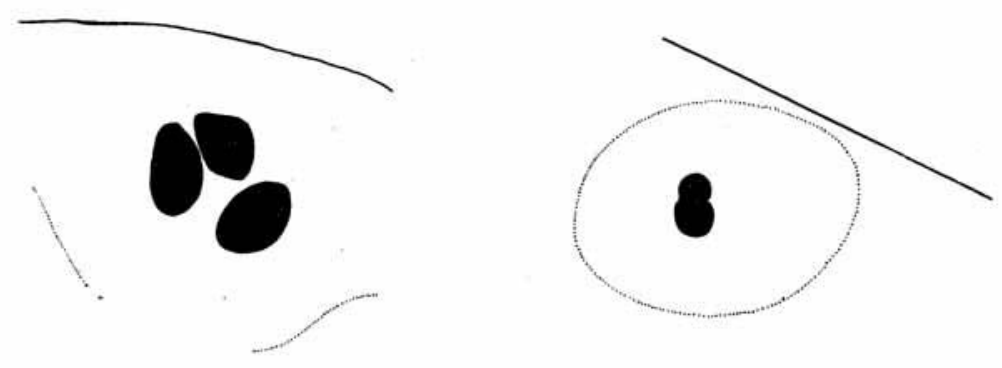

26
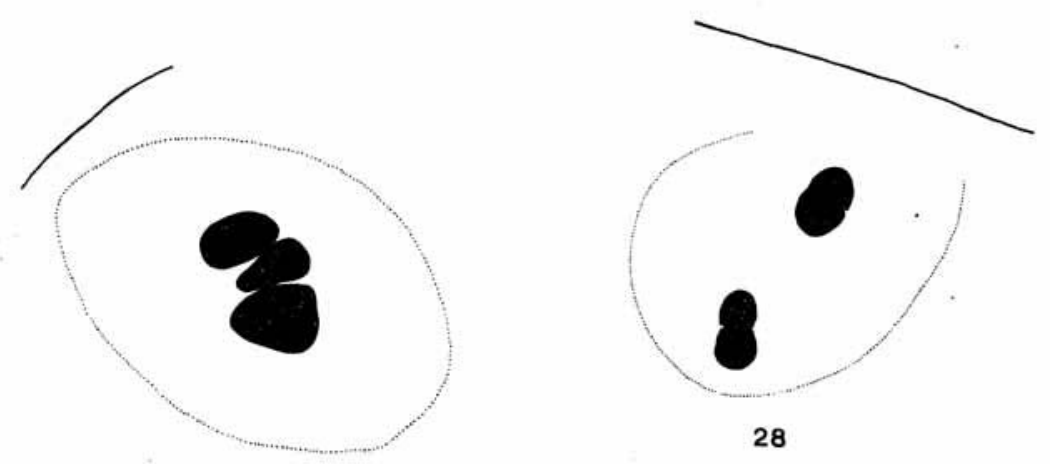

27

$x$ 's one might anticipate a similar change in the sexual egg. We must conclude, therefore, that one of the pairs in the sexual egg represents the fusion of the two large $X$ 's and their attached small $x$ 's. One large $X$ and one small $x$ would therefore be left 
in the egg. The female-producing sperm brings in during fertilization a large $X$ and a small $x$ which brings the number back to the six chromosomes (in reality eight since two are double, $X$ and $x$ ) of the stem-mother's soma.

\section{THEORETICAL INTERPRETATION OF THE RESULTS}

From the results given in preceding sections I draw the following conclusions. The cells of the stem-mother (that comes from the fertilized egg) contain six equal or nearly equal chromosomes. Two of these, that I call $X$, have attached to them two smaller chromosomes that I call small $x$. The stem-mother's cells have therefore in reality eight chromosomes. The eggs produced by the stem-mother also contain these six (or eight) chromosomes that appear in the equatorial plate of the polar body. One polar body is extruded. The division of the chromosomes has not been observed. I assume that at this time all of the chromosomes divide equally, except in the case of those eggs that will become male-egg producers. In these eggs one of the small $x$ 's passes undivided into the polar body. Presumably it passes out attached to the outgoing half of the larger $X$, with which it has been fused. Unless it separated from the large $X$ it might not appear as a lagging chromosome at the time; if it became detached it might appear as a lagging chromosome; or both the large outgoing half of the large $X$ with its attached small $x$ might lag behind the rest. Further work will be necessary to settle this point. This kind of egg, after the polar body is extruded, will contain six chromosomes, one having been reduced in size by the loss of the small $x$. This group appears in the equatorial plate of the polar spindle of the small 'male' egg. The difference in the size relations of the chromosomes observed in the polar spindle of this egg, as compared with the size relations of the chromosomes in the stem-mother's egg is accounted for by the loss of one chromosome - the small $x$. If eight chromosomes are present in the stem-mother's cells and eggs there are only seven in the body cells and in the eggs of the male-producers. When the polar body of the male-producing egg is formed all the chromosomes divide except one, which, Iagging on the spindle, finally passes 
Pluroncosomes of sten mothers polat spindle

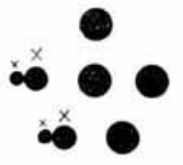

Two types (A $\mathrm{A}$ B) of division of atove to maduce the female line $A$ and the male lines.

Polar spindle of fenole producing egg. $A$; and male producing egg. B.

Somatic cetls of funte $\mathbf{A}$ and male $\mathbf{B}$.

\footnotetext{
Reduced number of Chomosmes in sexual eag.A;
} and in spermalonte $B$.

Dirision of Polar spindle wh sexual tog $A$. Fiot. disision of premalecte $\mathrm{B}$
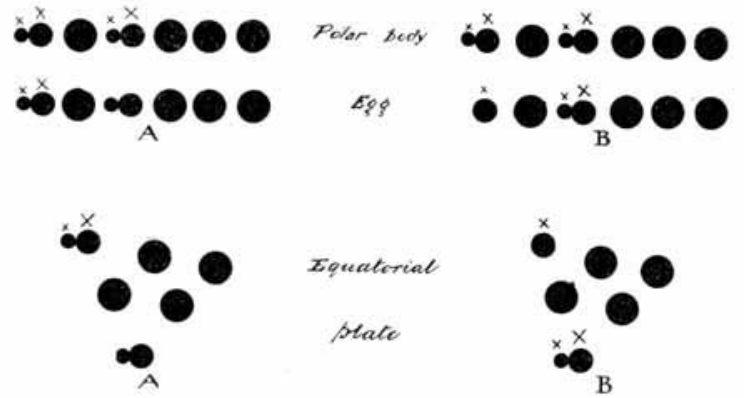

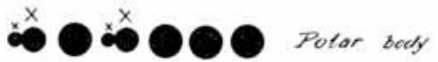

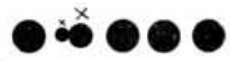

\%

คำ

ค
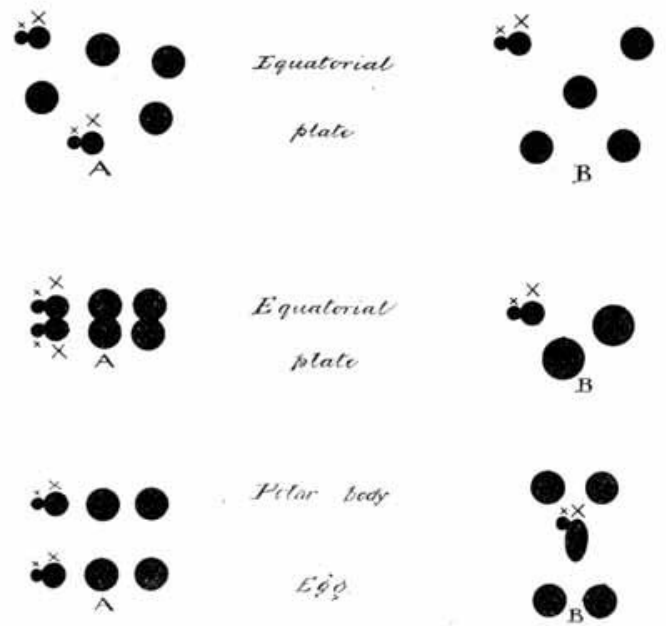

DIAGRAM 1 
out bodily into the polar body dividing at this time as do also the members of the outer group of chromosomes. The result is that five visible chromosomes remain in the male egg, in reality six chromosomes, since the large $X$ and the small $x$ are attached to each other. In the body cells of the male these two $X$ 's often remain united, but sometimes partially separate. When reduction takes place three visible chromosomes are present in the spermatocytes (one of these three is the fused pair). Two of these divide equally at the first division, and one (the fused pair) lags behind and finally passes to the female-producing sperm. Toward the end of this division the large $X$ and the small $x$, not infrequently partially or even completely separate. In the second spermatocyte division all the chromosomes of the female-producing cell divide equally, giving rise to two functional sperm containing three visible chromosomes, or four in reality since one is double. The class of cells without the $X$ 's degenerate.

Returning again to the stem-mother in order to trace the history of the female line I assume that when the polar spindle divides all of the eight chromosomes divide, leaving eight in the egg (six visible) of which there are two pairs, each containing a large $X$ and its attached small $x$. The eggs develop into the female producers, whose polar spindles contain six equal chromosomes like those of the polar spindle of the stem-mother. The larger number of chromosomes in the female-producing egg accounts for the larger size of the egg, as compared with the male-producing egg, which, as shown above, contains one less chromosome (the small $x$ ). When the polar body is set free the chromosomes divide equally, six (in reality eight) passing out, and six (or eight) remaining in the egg. The body cells of the sexual female contain therefore six (eight) chromosomes. A reduction division occurs in the sexual eggs, so that three (in reality four) chromosomes appear. When the polar bodies are formed-there are two of them to judge by analogy with the aphids - three whole chromosomes (in reality four) are given off at one of the divisions so that three (in reality four) remain in the egg. The femaleproducing spermatozoon introduces into this egg during fertili- 
zation the same chromosome group, which brings back the number of chromosomes to that characteristic of the stem-mother, and starts the same cycle again in the next year.

The attachment of the two small $x$ 's to the two large $X$ 's, that is assumed to occur throughout this series, except when one of the small $x$ 's is supposedly lost in the male-producing line of the stem-mother's egg, and the loss of one large $X$ when the male egg extrudes its polar body, may seem to be the most doubtful points in the preceding account: That a small $x$ is actually present is shown clearly in the spermatogenesis, and in some of the somatic cells of the male. It is, therefore, highly probable that the other large $X$, found in the stem-mother and female line, has also a small $x$ attached. Otherwise a symmetrical distribution of the chromosomes can not take place. But my assumption that one small $x$ is eliminated from those eggs of the stem-mother that give rise to the male line may appear more problematical. I readily grant that this is hypothetical. There are two facts, however, that give the hypothesis some probability. First, by means of this hypothesis the change in observed size-relations that takes place in the chromosome group of the male-producing egg can be accounted for. Second, the apparent absence of the small chromosome, in the lagging chromosome of the polar spindle of the male-producing egg, supports this view. On the basis of these two observations I have ventured to offer the above hypothesis, especially as it seems to give a consistent view of the changes that take place at the most critical stage in the life cycle when two lines are produced. In my former paper I have pointed out that there is no external condition that appears adequate to account for this dichotomy, and, if this is correct, we are warranted in looking for an internal factor that produces the result. The assumption moreover is in accord with the view, now well established, that the production of males is associated with the absence of certain chromatin in the egg. From this point of view the male-egg-producer - the winged migrant-is half a step towards the production of a male; the final step is taken when the other $X$ is eliminated, which demonstrably occurs at the next stage when the polar body of the male egg is eliminated. 
That an $X$ chromosome may be present attached to another chromosome has been shown in recent years by Boveri, Boring and Gulick in several species of Ascaris. The same looseness of attachment that I have observed has also been found in the eggs of Ascaris where in certain individuals and at certain times a separation has been recorded, while in other individuals the $X$ chromosome remains completely united with its larger companion. In my own case the attachment is between two $X$ chromosomes while in the other cases the attachment is between an $X$ and what is apparently an ordinary chromosome.

\section{OTHER POSSIBLE INTERPRETATIONS CONSIDERED}

In my former paper when dealing with the differences in the chromosomal groups in the equatorial plates of the polar spindles of the male- and female-producing eggs I have suggested that the change could be accounted for if in the male egg the two smallest chromosomes (the two small $x$ 's) each left its larger partner and fused together while the two larger also fused. This would give the same actual number as before, but a relative difference in size would result. The logical conclusion from the assumption would be that when the polar bodies are given off the large $X$ 's separate (reduction division for the pair) and the small $x$ 's also separate, the other chromosomes dividing equationally. This assumption was necessary for the large $X$ and the small $x$ pair because in the spermatogenesis a large $X$ and a small $x$ are still present.

If this view were correct the lagging chromosomes in the anaphase of the male egg should consist of a large and a small chromosome. The facts show that two chromosomes do actually lag but unfortunately for the assumption they are equal and relatively large. The doubleness of this lagging body can be better explained by a precocious division into equal parts, since the other chromosomes that pass out into the polar body also show signs of division at this time. It is clear that my former interpretation must be abandoned.

There is another interpretation that might be considered, namely, that the lagging body is really a large $X$ and small $x$ closely united 
and the division is equal in both as in the other chromosomes that pass out. This would leave a similar pair (large $X$ and small $x$ ) in the male-producing egg which becomes the lagging pair in the spermatogenesis. This hypothesis works out consistently but it leaves unexplained the observed size differences that appear in the chromosome groups of the male egg; it also leaves unaccounted for the production of the smaller male egg and it 'explains away' the observed size relations in the lagging chromosomes of the male egg. Hence I think this view must also be put aside.

Again we might assume that the large $X$ is the sex chromosome and the small chromosome attached to it (its synaptic mate) is in reality not an $X$ at all, but a $Y$ chromosome. Were this the case the $Y$ should pass into the male-producing sperm since this is the characteristic behavior of $Y$ in other insects. As it does not do so there is no basis of fact to support such an interpretation.

Lastly, one may ask whether the two large $X$ 's in the stemmother's egg are of the same size and also whether the two small $x$ 's present are of the same size. Assume for instance that the two smaller $x$ 's are unequal in size. If the larger of them should pass out into the polar body of the stem-mother's egg the egg might become a male-egg-producer, if the smaller passes out the egg might become a female-egg-producer. In this way the two lines become differentiated. But this would leave in the female line two $X$ 's and one small $x$ (the larger one). We should have to assume then that the sexual egg eliminates one large $X$ and retains the other large $X$ and the other $x$ (its companion). In other words a second differential division must be assumed. In the absence of evidence we are scarcely justified in making two such assumptions. Moreover, if this view were correct we should expect to find a chromosome group in the polar spindle of the female producing egg like that in the male-producing egg, but this is what we do not find. Of course if the larger of the small $x$ 's that is assumed to be left in the female-egg-producer were much larger than that left in the male-egg-producer the size differences might not be so marked, but until this can be established we are 
scarcely justified in making this assumption even although by doing so we may seem to give an attractive explanation of the splitting into the male and female lines.

Other combinations will suggest themselves but offer no advantages I believe over the one that I have suggested.

\section{COMPARISON BETWEEN PHYLLOXERA CARYAECAULIS AND PHYLLOXERA FALLAX}

It may be worth while to compare briefly the conclusions reached for P. caryaecaulis with the results described in my former paper for another species, P. fallax. The latter has twelve chromosomes in the equatorial plate of the egg laid by the stemmother. After the extrusion of the polar bodies I have described twelve chromosomes as the number for the cells of the embryo. If as in P. caryaecaulis there are two pairs of $X$ 's present that are united this number would still be found, but if this view were correct for the male line we should expect to find six in the male spermatocytes of which one is double. Five should divide equally and the double one should lag with or without showing its doubleness at this time. In reality only four divide equally and two whole chromosomes that were separate in the equatorial plate of the spermatocyte come near together and become the lagging chromosomes of this division. There can be no question of their relations in the spermatocytes since the chromosomes are perfectly distinct and hundreds of such stages have been studied. It seems necessary therefore to recast this first view and to reëxamine the facts. In fig. II; $A-F$ of my paper six chromosome groups of polar spindles of male- and female- producing eggs are drawn. Of these groups three show twelve chromosomes, two. show eleven, and one is doubtful. In fig. II a; $C-T$ there are nine groups showing twelve chromosomes, one is doubtfully tweive or eleven, one shows eleven, and one shows ten. These are all from winged individuals. These retain their eggs for some days and several ripe eggs are found in the body of each individual, while the wingless individuals, which have replaced largely the winged in this species, bring to maturity only one egg at a time which is laid as soon as it is ripe. It is therefore more difficult 
to get polar body spindles in this type. The winged individuals produce only male eggs, so far as I have found. Therefore the fifteen equatorial plates of the winged migrants supposedly belong to male eggs. Now it is well recognized that the large number of chromosomes is more likely to represent the typical number, for, when one or two are lacking they may be in other sections, or be cut, or obscured by the other chromosomes. It appears then that twelve chromosomes are present in the male eggs.

I found only two cases in wingless individuals in which the number of chromosomes could be clearly counted, fig. II a $U$ and $W$. In both ten chromosomes are present, but two are of double size and probably represent the four $X$ 's fused together in two pairs. There is no visible evidence therefore of the loss of one chromosome in the eggs that give rise to the male-producers as I have postulated for P. caryaecaulis.

After the polar bodies have been given off from the large and the small eggs - unfortunately I have never found a spindle in process of division - two kinds of embryos are found, namely, those containing twelve and those containing ten chromosomes. It appears therefore that two chromosomes are lost from the smaller egg. Morever only ten chromosomes appear in the spermatogonial cells. The evidence therefore may seem to point to the conclusion that in this species there is usually no loss of chromosomes in any of the eggs (at least none that can be pointed out) of the stem-mother at the time when the polar bodies are formed. Hence the separation into the male-producers and the female-producers at this time can not be shown to be due to the loss of one of the twelve visible chromosomes.

It may appear therefore that the evidence contradicts the hypothesis offered to account for the change in the other species, but it will be noticed that the comparison rests in the assumption that the two equal $X$ chromosomes in the spermatocytes of $P$. fallax correspond to the large $X$ and the small $x$ of $P$. caryaecaulis. But it may equally well be true that there are two large $X$ 's with two small $x$ 's attached (that do not become visible) in $\mathrm{P}$. fallax. In other words not only are there twice as many ordinary chromosomes but twice as many sex chromosomes also. The 
total number of one species is double that of the other. If this is the case the loss of the two smaller $x$ 's might take place in those eggs of the stem-mother that give rise to the male producers and its loss might not be apparent unless its mate were sufficiently reduced in size to make its loss visible. It has not been possible to make out the size relations of the chromosomes in P. fallax with sufficient clearness for the evidence to be of any value one way or the other. The question for this species must be left unanswered, but it should at least be noticed that the two large lagging chromosomes of $P$. fallax behave like the single lagging chromosomes of $\mathrm{P}$. caryaecaulis, and not like the large $X$ and the small one of the latter form. 